\title{
Stickoxydul in flüssiger und fester Form.
}

Dumas hat mittolst eines starken CompressionsApparates das sog. oxydirte Stickgas zu einer Flissigheit zusammengepresst und folgende Erfahrungen darüber mitgetheilt: Soll das Zusammendrücken des oxydirten Stickgases zu ciner Flussigkeit gut von Statten gehen, so muss es sehr trocken und möglicbst rein sein. Du mas bereitet es aus Ammoniaknitrat und bewahrt es in luftdichtem Leinen auf, aus welchem die Pumpe es wieder aufnimmt. Es lässt sich als comprimirte Flüssigkeit wenigstens zwei Tage lang aufbewahren. Oeffnet man den Hahn des Behälters am Apparat. so entweicht Gas und gefriert sofort. Iyer Rückstand bleibt fliissig. Der gefrorne Theil in Masse gleicht dem Schnee, schmilzt auf der Hand, verfluichtigt sich hier plötzlich und hinterlässt ein heftiges Brennen. Der fliissige Theil hält sich an freier Luft fast eine halbe Stunde lang. Ueber mit Schwefelsaure befeuchtetem Bimsteinpulver bewahrt er seine Durchsichtigkeit sehr lange. Er ist farblos, sehr beweglich und volikommen durchsichtig Jeder auf die Haut fallende Tropfen des. selben verursacht hier ein heftiges Brennen. Das sich aus dieser Fliissigk eit mit langsamem Aufwallen ent wickelnde Gas hat alle Eigenschaften des Stickstoffprotoxyds $\left(\mathrm{N}^{2} \mathrm{O}\right)$. Metalle mit dieser Flüssigkeit in Beriihrung gebracht, verursachen ein Brausen, wie das des gliuhenden in Wasser getauch¿en Eisens. Auch das Quecksilber bewirkt ein ähnliches Brausen darin, erstarrt sofort und wird zur harten, zerbrechlichen, silberglinzenden Masse. Kalium schwimmt darauf, ohne eine Veründerung zu erleiden; eben so verhält sich Kohle, Schwefel, Phosphor und Jod. Angezündete Kohle brennt darauf schwimmend mil lebhaftem Glanz rein auf. Schwefelsäure und concentrirte Salpetersäure erstarren sofort damit. Aether und Weingeist vermischen sich damit, ohne zu gefrieren. Wasser wird darauf sogleich zu Eis, bewirkt aber eine so plötzliche Dampfentwickelung, dass diese einer Explosion gleicht, welche gefährlich sein würde, wenn man unvorsichtig genug wäre, auf einmal ein Paar Grammen Wasser in die Flüssigkeit zu giessen. (Journ. de Pharm. et de Chim. 1848. p. 4ll.) du Mênil.

\section{Notiz über unterchlorige Säure und Chlorschwefel.}

Chlorwasser erhält sich im Dunkeln olne eine merkliche Veränderung; wird dasselbe aber einige Zeit lang den Sonnenstrahlen ausgesetzt, so hat es andere Reac- 